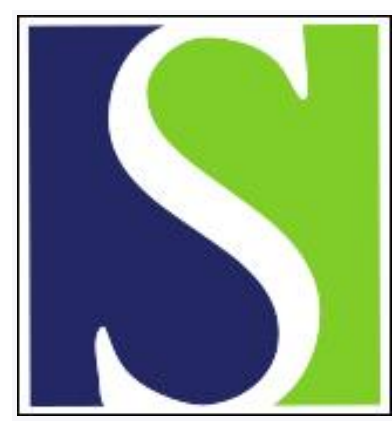

Scand J Work Environ Health 2018;44(5):441-442

https://doi.org/10.5271/sjweh.3764

Published online: 06 Aug 2018, Issue date: 01 Sep 2018

Could we have better occupational health guidelines, please? by Verbeek J

Affiliation: Finnish Institute of Occupational Health, Cochrane Work, Kuopio, Finland. jos.verbeek@ttl.fi

Refers to the following texts of the Journal: 2018;44(3):323-329 2018;44(5):443-457

Key terms: bias; editorial; evidence-based medicine; methodology; occupational health; occupational health guideline

This article in PubMed: www.ncbi.nlm.nih.gov/pubmed/30079429 


\section{Could we have better occupational health guidelines, please?}

According to Wiktionary, a guideline is a plan to guide one in setting standards or determining a course of action. In occupational safety and health (OSH), there are two basic problems for which guidance can be helpful. The first is under which circumstances or exposures a worker is at risk of adverse health effects. The second is which actions can be taken to ensure that a worker is safe from these risks. For both problems, one would like to see solid evidence: first that there is a risk and then that interventions can keep workers safe. Very similar problems exist in environmental health, nutrition and water safety.

We have long relied on expert advice to tackle these problems. However, it has also long been recognized that expert advice can be seriously biased due to financial conflicts of interest, for example, such as those created by the asbestos or tobacco industries and their consultants (1). Strong beliefs in one specific approach can also lead to bias and blindness in seeing also other sides of a problem and can thus create an intellectual conflict of interest. It won't come as a surprise that there is a wide variation in expert judgments across a range of fields, including healthcare (2), and that experts are quite bad at making predictions (3). Expert-based recommendations for biomechanical risk factors at work from the International Standard Organization (ISO) have also been criticized for not being based on scientific evidence (4).

To prevent expert bias in evidence synthesis, around three decades ago systematic review methodology was developed (5). To prevent expert bias in making recommendations, the GRADE working group developed thorough methods for drafting guidelines for healthcare practitioners (6). The process starts with defining PICO questions (the four elements that are important for almost any research question: population, intervention/exposure, comparison and outcome) to make sure focus is placed on the right question to get the correct answer. Based on the PICO question, systematic reviews of the evidence are conducted. The reviews enable an unbiased - or a least-biased - conclusion on the effects of the intervention or exposure and on the quality of the underlying evidence. The next step is to translate the evidence into concrete recommendations that form the backbone of a guideline. The recommendations are first informed by the balance of the beneficial and adverse effects as reported by the systematic review but also by the quality of the evidence, preferences and values of those involved and the feasibility and costs of the interventions. This method has also been recommended for environmental and occupational risks and has been applied, with some adaptation, to environmental noise guidelines $(7,8)$.

Since 2009, the World Health Organization (WHO) has adopted the policy that all their guidelines must be based on systematic reviews of the evidence and on GRADE guidance for developing recommendations. The rules for guideline development have been laid down in a WHO guideline development handbook (9). Guidelines that have been developed according to the handbook have been evaluated and have been shown to be resistant to bias from industry (10). Based on these principles, the WHO recently developed a guideline on managing the potential risks of manufactured nanomaterials (11). In some countries, such as The Netherlands, guidelines have been developed to assist occupational health practitioners in the management of occupational health conditions based on a similar evidence-based approach (12).

In this issue of the Scandinavian Journal of Work, Environment and Health, Nexo et al (13) systematically reviewed and appraised guidelines to assist employers and workers in preventing or decreasing mental health problems at work. In the eight guidelines on primary prevention they located, only two based their recommendations on a systematic review of the evidence. One of these guidelines was developed ten years ago and the evidence is most certainly outdated. Interestingly, the guidelines only considered evidence of risks of adverse health effects and not evidence of the effectiveness of the recommended interventions. However, we know that evidence for OSH interventions is available (14) (see work.cochrane.org). It is especially disturbing that the guidelines published by the European Union in 2014, as a trusted source of information, were of the lowest quality and did not use systematic review of the evidence. Even though the EU supports evidence-based policy, this does not seem to be the case in OSH. Moreover, Nexo et al also found evidence that a number of the published recommendations would not be effective. This is another reason why regular updating of guidelines is important.

All in all, it seems that for guidelines aiming at preventing and decreasing mental health problems at work, the era of evidence-based medicine has yet to start. Given the size of the problem, with depression being the leading cause of disability among workers in most countries, there is an urgent need to develop guidelines of better methodological quality. The tools are available and recent WHO guidelines show that these tools can be applied also in OSH. 


\title{
References
}

1. Michaels D. Doubt is their product, how industry's assault on science threatens your health. Don Mills ON, Canada: Oxford University Press US; 2008.

2. Sutherland WJ, Burgman M. Policy advice: use experts wisely. Nature 2015 Oct;526(7573):317-8. http://dx.doi.org/10.1038/526317a.

3. Tetlock P. Expert Political Judgment: How Good Is It? How Can We Know? Princeton (NJ) USA: Princeton Univesity Press, 2005.

4. Armstrong TJ, Burdorf A, Descatha A, Farioli A, Graf M, Horie S, et al. Scientific basis of ISO standards on biomechanical risk factors. Scand J Work Environ Health 2018 May;44(3):323-9. http://dx.doi.org/10.5271/sjweh.3718.

5. Oxman AD, Guyatt GH. Guidelines for reading literature reviews. CMAJ 1988 Apr;138(8):697-703.

6. Guyatt GH, Oxman AD, Vist GE, Kunz R, Falck-Ytter Y, Alonso-Coello P, et al.; GRADE Working Group. GRADE: an emerging consensus on rating quality of evidence and strength of recommendations. BMJ 2008 Apr;336(7650):924-6. http://dx.doi. $\operatorname{org} / 10.1136 /$ bmj.39489.470347.AD.

7. Morgan RL, Thayer KA, Bero L, Bruce N, Falck-Ytter Y, Ghersi D, et al. GRADE: assessing the quality of evidence in environmental and occupational health. Environ Int 2016 Jul-Aug;92-93:611-6. http://dx.doi.org/10.1016/j.envint.2016.01.004.

8. Jarosińska D, Héroux ME, Wilkhu P, Creswick J, Verbeek J, Wothge J, et al. Development of the WHO Environmental Noise Guidelines for the European Region: an Introduction. Int J Environ Res Public Health 2018 Apr;15(4):E813. http://dx.doi. org/10.3390/ijerph15040813.

9. World Health Organization. WHO handbook for guideline development, 2nd ed. 2nd ed. Geneva, Switzerland: World Helath Organization 2014.

10. Norris SL, Ford N. Improving the quality of WHO guidelines over the last decade: progress and challenges. Lancet Glob Health 2017 Sep;5(9):e855-6. http://dx.doi.org/10.1016/S2214-109X(17)30253-X.

11. World Health Organization. WHO guidelines on protecting workers from potential risks of manufactured nanomaterials. Geneva, Switzerland: World Health Organization, 2017.

12. Kuijer PP, Verbeek JH, Visser B, Elders LA, Van Roden N, Van den Wittenboer ME, et al. An Evidence-Based Multidisciplinary Practice Guideline to Reduce the Workload due to Lifting for Preventing Work-Related Low Back Pain. Ann Occup Environ Med 2014 Jun;26:16. http://dx.doi.org/10.1186/2052-4374-26-16.

13. Nexø MA, Kristensen JV, Grønvad MT, Kristiansen J, Poulsen OM. Content and quality of workplace guidelines developed to prevent mental health problems: results from a systematic review. Scand J Work Environ Health. 2018;44(5):443-457. http://dx.doi. org/10.5271/sjweh.3731.

14. Ruotsalainen JH, Verbeek JH, Salmi JA, Jauhiainen M, Laamanen I, Pasternack I, et al. Evidence on the effectiveness of occupational health interventions. Am J Ind Med 2006 Oct;49(10):865-72. http://dx.doi.org/10.1002/ajim.20371.

\author{
Jos Verbeek, \\ Finnish Institute of Occupational Health \\ Cochrane Work \\ Kuopio, Finland \\ [E-mail: jos.verbeek@ttl.fi]
}

